\title{
Studies on Fumarase
}

\section{THE EFFECTS OF INHIBITORS ON FUMARASE ACTIVITY}

\author{
By V. MASSEY \\ Sir William Dunn Institute of Biochemistry, University of Cambridge
}

(Received 28 October 1952)

In recent years much use has been made of competitive inhibitors as tools for investigating the mode of action of enzymes. However, there has been little systematic study of the variation of inhibition with such factors as temperature and $\mathrm{pH}$. Such a study might be expected to throw valuable light on the mechanism of a particular enzymic reaction, since it would be expected to yield information about the thermodynamics of the process and, from the recent theory of Dixon (1953), about the changes in electrical charge accompanying both activation and inhibition. In this paper is described the result of such an investigation with fumarase.

\section{METHODS}

The results reported here have been obtained with crystallized fumarase using the method of activity determination already described (Massey, 1953a). All the activity values used were initial velocities. The temperature was controlled to within $\pm 0 \cdot 1^{\circ}$ by means of an apparatus designed by Dr M. Dixon, F.R.S. This device, which comprises a cell holder through which water from a constant-temperature bath is circulated, will be described in detail by Dr Dixon in a later communication. Unless otherwise stated, all the results were obtained in the presence of $0.06 \mathrm{M}$-phosphate buffers. It has been shown (Massey, 1953 $a$ ) that the initial velocity of the fumarase reaction decreases in the presence of large amounts of phosphate. This seems to be a non-specific effect of ionic strength; accordingly, care had to be taken that the total ionic strength of the reaction mixture was not too high. This limits the accurate determination of the inhibitor constants of weak inhibitors, as the highest concentration at which they can be safely tested, without nonspecific salt inhibition, is in the vicinity of $0.1 \mathrm{M}$. In all cases reported in this paper the total ionic strength has been kept below $0 \cdot 3$. The method used for determining the type of inhibition was that of Lineweaver \& Burk (1934) in which the reciprocal of the initial velocity is plotted against the reciprocal of the substrate concentration. The inhibitor constant $\left(K_{i}\right)$ of a competitive inhibitor, which is a dissociation constant of the enzyme-inhibitor complex $(E I)$, was calculated from the Lineweaver \& Burk plots by the formula

$$
K_{i}=\frac{[I] \times K_{m}}{\left(K_{p}-K_{m}\right)},
$$

where $[I]$ is the concentration of inhibitor; $K_{m}$ is the Michaelis constant and $K_{p}$ is the apparent Michaelis constant in the presence of the particular concentration of inhibitor used.

\section{RESULTS}

The following substances have been tested in this work and are classified into the types of effect which they produce.

Competitive inhibitors. The sodium salts of $\mathrm{D}$ malic, trans-aconitic, citric, mesaconic, maleic, adipic, glutaric, succinic, malonic and $\mathrm{D}$-tartaric acids, glycine, and the sodium salt of $L-\alpha-h y d r o x y-$ $\beta$-sulphopropionic acid (the deaminated derivative of L-cysteic acid, L-ethane-1-carboxy-1-hydroxy-2sulphonic acid).

Non-competitive inhibitors. Thiocyanate, the sodium salt of acetylenedicarboxylic acid.

Non-inhibitory. The sodium salts of acetic, butyric, crotonic, L- and DL-aspartic and acetoacetic acids, the mono- and di-methyl esters of fumarate; and the SH inhibitors, iodoacetate, iodoacetamide, iodosobenzoate, $p$-chloromercuribenzoate and chloroacetophenone.

Table 1 shows the inhibitor constants at pH 6.35 and $23^{\circ}$ of compounds which have been found to behave strictly as competitive inhibitors of fumarase.

Table 1. The effect of structure on inhibition of fumarase at $\mathrm{pH} 6.35$ and $23^{\circ}$

$\begin{array}{ll}\quad \text { Inhibitor } & K_{i} \text { (molar) } \\ \text { Adipate } & 1.0 \times 10^{-1} \\ \text { Succinate } & 5.2 \times 10^{-2} \\ \text { Glutarate } & 4.6 \times 10^{-2} \\ \text { Malonate } & 4.0 \times 10^{-2} \\ \text { D-Tartrate } & 2.5 \times 10^{-2} \\ \text { Mesaconate } & 2.5 \times 10^{-2} \\ \text { L- } \alpha \text {-Hydroxy- } \beta \text {-sulpho- } & 1.65 \times 10^{-2} \\ \text { propionate } & \\ \text { Maleate } & 1.1 \times 10^{-2} \\ \text { D-Malate } & 6.3 \times 10^{-3} \\ \text { Citrate } & 3.5 \times 10^{-3} \\ \text { trans-Aconitate } & 6.3 \times 10^{-4}\end{array}$

Within the limits of experimental error the inhibition constants of the reagents tested are the same whether the substrate is fumarate or L-malate. This is taken as evidence that (as might be expected) the same active sites on the enzyme are concerned with the hydration of fumarate as with the dehydration of I-malate. 


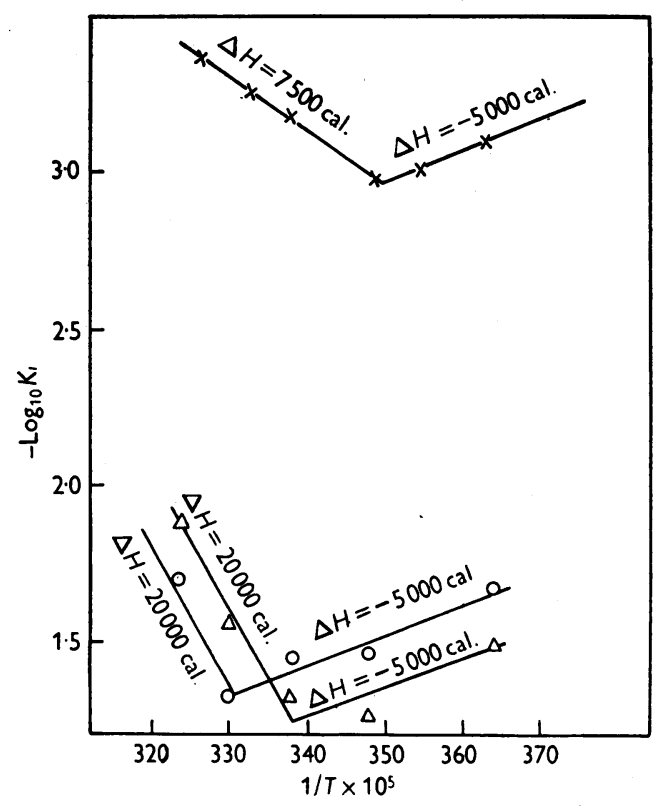

Fig. 1. The effect of temperature on $K_{i}: \times$,trans-aconitate; $\triangle$, succinate; $O$, malonate.

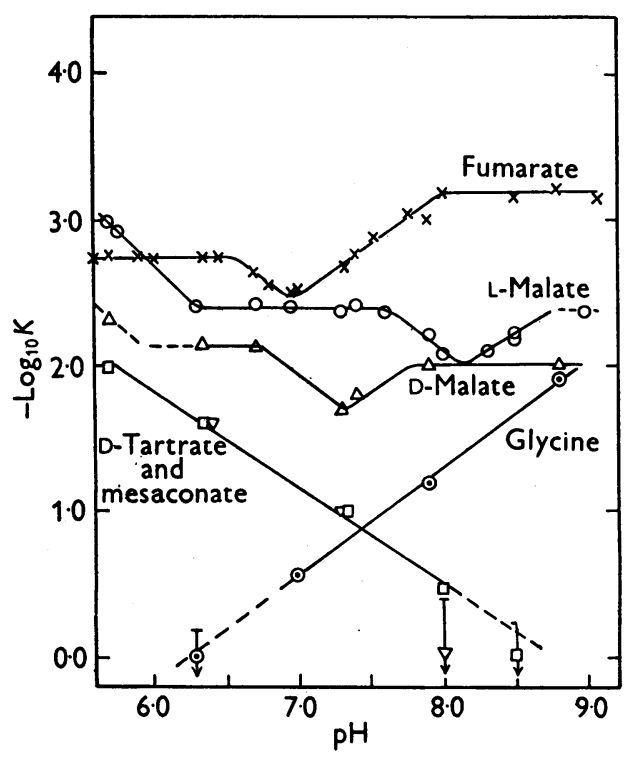

Fig. 2. The effect of $\mathrm{pH}$ on $K_{m}$ and $K_{i}$ at $23^{\circ} . K$ denotes $K_{m}$ for fumarate and L-malate, and $K_{i}$ for the other substances. Signs of the type $\underset{\downarrow}{T}$ indicate the range of accuracy of the experimental point, the arrow indicating that the value of $-\log _{10} K$ may lie anywhere in the direction of the arrow. $\times$, Fumarate; $O$, L-malate; $\triangle$, D-malate; $\square$, D-tartrate; $\nabla$, mesaconate; $\odot$,glycine.

\section{The effect of temperature on inhibition}

The inhibition by all the reagents tested varied with temperature. Fig. 1 shows the effect of temperature on the inhibition constants of trans. aconitate, succinate and malonate at $\mathrm{pH} 6.35$. It is seen that at low temperatures the combination of enzyme and inhibitor is exothermic, while at higher temperatures the combination is endothermic. A similar phenomenon occurs with the combination of fumarate and enzyme at acid $\mathrm{pH}$ values (Massey, $1953 b$ ). There, however, the combination of enzyme and substrate was endothermic over the range of temperature investigated $\left(2-35^{\circ}\right)$, but at about $18^{\circ}$ there was a changeover from a low heat of formation of the enzyme-substrate complex $(E S)$ at low temperatures to a higher heat of formation at higher temperatures.

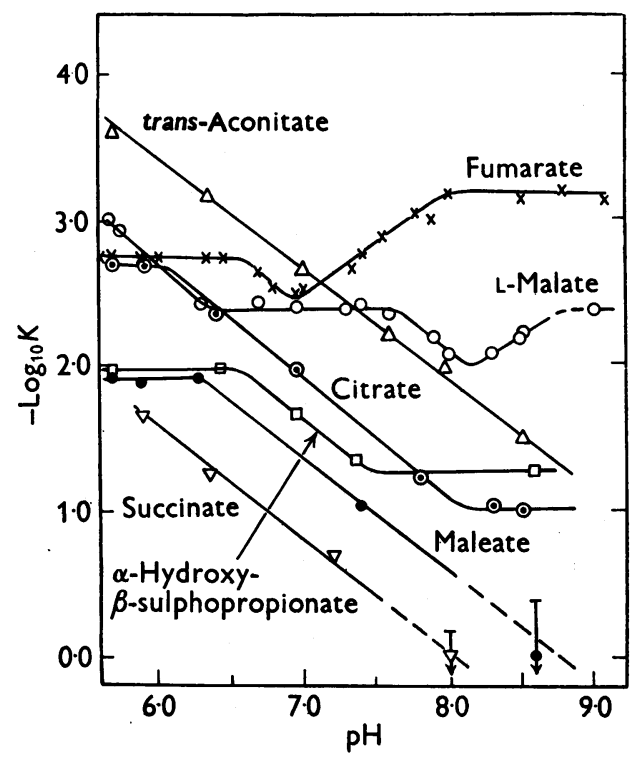

Fig. 3. The effect of $\mathrm{pH}$ on $K_{m}$ and $K_{i}$ at $23^{\circ} . K$ denotes $K_{m}$ for fumarate and L-malate, and $K_{i}$ for the other substances. Signs of the type $\downarrow$ indicate the range of accuracy of the experimental point, the arrow indicating that the value of $-\log _{10} K$ may lie anywhere in the direction of the arrow. $x$, Fumarate; $O$, L-malate; $\triangle$, trans-aconitate; $\odot$, citrate; $\square$, L- $\alpha$-hydroxy- $\beta$ sulphopropionate; 0 , maleate; $\nabla$, succinate.

\section{The effect of $\mathrm{pH}$ on inhibition}

A decrease in the inhibition as the $\mathrm{pH}$ was shifted toward alkaline values was observed with several inhibitors, and led to a detailed study of the effect of $\mathrm{pH}$ on the inhibitor constants of competitive inhibitors of fumarase. Figs. 2 and 3 show the effect of $\mathrm{pH}$ at $23^{\circ}$ on the dissociation constants $\left(K_{i}\right)$ of a number of inhibitors. These figures also show 
for comparison the effect of $\mathrm{pH}$ at this temperature on the $K_{m}$ values for both fumarate and L-malate.

$D$-Malate is the only inhibitor found to behave in an analogous way to the natural substrates. The dissociation constants of these three compounds with fumarase were found to be independent of $\mathrm{pH}$ over a certain range, then with increasing alkalinity to increase, pass through a maximum (corresponding roughly in the case of the two natural substrates to the $\mathrm{pH}$ of optimal activity), then to decrease and finally to become once more independent of $\mathrm{pH}$. The $K_{i}$ values of trans-aconitate, tartrate, mesaconate and succinate all continue to increase when the $\mathrm{pH}$ is shifted toward alkaline values, until at $\mathrm{pH} \mathrm{8.5}$ trans-aconitate is the only one of these compounds to show any appreciable inhibition.

With maleate the inhibition is constant over the $\mathrm{pH}$ range $5 \cdot 7-6 \cdot 4$, then it decreases as the $\mathrm{pH}$ is increased. The variation of inhibitory behaviour with $\mathrm{pH}$ of citrate and $\alpha$-hydroxy- $\beta$-sulphopropionate is also of a different type. Within the range of phosphate buffers, as the $\mathrm{pH}$ is increased their inhibition is at first constant, then decreases and finally becomes independent of $\mathrm{pH}$ once more.

The effect of $\mathrm{pH}$ on the inhibition by glycine is quite different. At $\mathrm{pH} 6.35$ there is no detectable inhibition, as the $\mathrm{pH}$ is made more alkaline, glycine begins to inhibit, and at $\mathrm{pH} 8.5$ the inhibition is quite strong.

\section{DISCUSSION}

No explanation of the observed behaviour of inhibition with temperature is obvious at present. The results do demonstrate the care which must be taken in the interpretation of inhibition results. Over a certain temperature range succinate is a more potent inhibitor than malonate, but over another range of temperature the converse is true. The same thing is true of the effect of $\mathrm{pH}$ on the activity of some inhibitors. If inhibition constants are determined at only one temperature and one $\mathrm{pH}$, as is often the case, highly erroneous conclusions may be drawn.

The results taken as a whole indicate that the combination of enzyme and substrate or enzyme and inhibitor is largely ionic in nature, or that at least an initial ionic attraction is necessary before combination can occur. Thus a large number of ionized acids ranging in size from $\mathrm{C}_{3}$ to $\mathrm{C}_{6}$ can combine with fumarase, and the extent of this combination is influenced greatly by $\mathrm{pH}$. When the ionization of one of the acidic groups is suppressed, then the inhibition, and hence combination of enzyme and acid, is also suppressed. Thus neither the monomethyl ester nor the dimethyl ester of fumarate is acted on by fumarase, nor are they inhibitory. Also crotonate, which resembles fumarate except that one of the carboxyl groups is replaced by a methyl group, does not combine at the active centre. Similarly, aspartic and cysteic acids, which under the $\mathrm{pH}$ conditions tested are strongly dipolar at one end of the molecule (and hence may be considered as approaching monoionized acids), do not combine at the active centre. Hence it appears that a two-point attraction of the substrate or inhibitor to the active centre is necessary for combination to occur.

The importance of the ionic attraction of the enzyme and substrate in the formation of a complex is shown also by the inhibition produced by $L-\alpha-$ hydroxy- $\beta$-sulphopropionate. This molecule is identical with L-malate except that the carboxyl group further away from the hydroxyl group is replaced by a sulphonic acid group. The fact that it will combine at the active centre indicates that a carboxyl group of L-malate may be replaced by a sulphonic acid group, and combination will still occur. The fact that this compound is not acted on by fumarase is further evidence of the great specificity of this enzyme and is indicative of the sensitive ionic balance that must be required for the catalytic action of the enzyme.

The most obvious ionic attaction would be between the ionized carboxyl groups of the substrate and positively charged groups in the protein. As neither crotonate nor the monomethyl ester of fumarate will cause any inhibition, presumably a two-point attachment of enzyme and substrate or enzyme and inhibitor must occur. However a threepoint attraction of such compounds as transaconitate and citrate may occur, and be responsible for their great affinity for fumarase.

An interpretation of the $\mathrm{pH}$ behaviour of the inhibitors and the substrates can be obtained in the light of the theory developed by Dixon (1953). This theory, which is a development of his theory of $\mathrm{rH}$ and $\mathbf{r} P$ (Dixon, 1950), applies the principles developed in these concepts to the combination of enzyme with substrates and inhibitors. From this theory the ionization constants ( $\mathrm{p} K$ 's) of various groups in the enzyme, substrate or enzyme-substrate complex can be obtained. This information is obtained from the plot of $\mathrm{p} K_{m}$ or $\mathrm{p} K_{i}$ against $\mathrm{pH}$. Such plots are shown in Figs. 2 and 3. A zero slope indicates that the number of charges on $E S$ is equal to the number on the free enzyme plus the number on the substrate; a negative slope of unity means that the free enzyme and free substrate contain one more negative charge than $E S$; the converse is true for a positive slope. Changes from one slope to another represent ionization constants : a change of the type concave side downward shows a $\mathrm{p} K$ value of some group in the free enzyme or the free substrate (or inhibitor); a change of the type concave side upward shows a $\mathrm{p} K$ value of some group of $E S$ or EI. An examination of Figs. 2 and 3 shows the 
existence with fumarase of all three kinds of slopes, and $\mathrm{p} K$ values for both free enzyme and $E S$ and $E I$.

With fumarate as substrate there is no change of $K_{m}$ between pH's 5.6 and 6.6. At $\mathrm{pH} \mathrm{6.6} \mathrm{there} \mathrm{is}$ a changeover to a negative slope which approximates to a one-unit slope. At $\mathrm{pH} 7 \cdot 0$ this changes over to an approximately one-unit positive slope, which continues until pH 8 where $K_{m}$ again becomes independent of $\mathrm{pH}$. This means that $\mathrm{pH} 6.6$ is a $\mathrm{pK}$ value of either fumarase or fumarate. As the $\mathrm{pK}$ values of fumarate are at $\mathrm{pH}$ 's 3.0 and 4.3 at this temperature, this means that fumarase has a group with a $\mathrm{p} K$ value of 6.6 at the active centre. $\mathrm{pH} 7 \cdot 0$ must represent the $\mathrm{p} K$ values of two groups in the enzyme-fumarate complex, as there is a changeover from a negative to a positive slope. Similarly, $\mathrm{pH} 8$ must represent a $\mathrm{p} K$ value of a group in the free enzyme as fumarate has no dissociation constant at this $\mathrm{pH}$ value.

The change with $\mathrm{pH}$ of the $K_{m}$ of L-malate is similar except that the whole curve is shifted to higher $\mathrm{pH}$ by about one unit. Thus the first $\mathrm{pK}$ value for the free enzyme occurs at about $\mathrm{pH} \mathbf{7 . 5}$ and the two $\mathrm{p} K$ values for the enzyme-malate complex at about $\mathrm{pH}$ 8. Also, another $\mathrm{p} K$ value of $E S$ has shown up at $\mathrm{pH} 6 \cdot 3$, which does not occur with fumarate in the $\mathrm{pH}$ range studied, and the second $\mathrm{p} K$ value for the free enzyme (which occurs at $\mathrm{pH} 8$ when fumarate is the substrate) has not shown up clearly in the range of phosphate buffers.

Of the inhibitors D-malate is the only one to behave in a similar way to the substrates, that is with positive, negative and zero slopes. The $\mathrm{p} K$ values of fumarase determined in the presence of $\mathrm{D}$-malate are at about $\mathrm{pH}$ 's 6.8 and 8.0 ; the $\mathrm{p} K$ values of $E I$ are at about $\mathrm{pH} 7 \cdot 3$ and perhaps in the neighbourhood of $6 \cdot 0$.

Citrate and $\alpha$-hydroxy- $\beta$-sulphopropionate show $\mathrm{p} K$ values for the free enzyme at $\mathrm{pH}$ 's 6.0 and 6.6 respectively, and $\mathrm{p} K$ values for $E I$ at $\mathrm{pH}$ 's $8 \cdot 1$ and $\mathbf{7 . 5}$ respectively. However, they give only one $\mathrm{p} K$ value each for free enzyme and $E I$, compared with at least two of each shown with fumarate, L-malate and D-malate.

trans-Aconitate does not give any $\mathrm{p} K$ value of either free enzyme or $E I$ over the whole $\mathrm{pH}$ range investigated $(5 \cdot 7-8 \cdot 5)$. Similar results were obtained with D-tartrate, mesaconate and succinate. With these last compounds, however, the possibility of a $\mathrm{p} K$ value of the free enzyme or $E I$ is not ruled out owing to the difficulty of obtaining an accurate value for $K_{i}$ when the inhibition is very small, as there is a limit to the concentration of inhibitor which can be used.

The results with maleate indicate a $\mathrm{p} K$ value of either fumarase or maleate at $\mathrm{pH} \mathrm{6 \cdot 4}$. Maleic acid has in fact a $\mathrm{p} K$ of about this value.
Glycine behaves in the opposite manner to transaconitate, etc., giving a positive slope of almost unity, indicating that the fumarase-glycine complex contains one more negative charge or one less positive charge than the free enzyme and glycine.

As both substrates and inhibitors yield different $\mathrm{p} K$ values for the free enzyme it is probable that the combination of the enzyme with these inhibitors or substrates alters the ionization constants of groups in the protein. This could conceivably occur by combination at two different sites in the enzyme, at the active centre and at some other site. The combination at the other site might quite well modify the ionization constants of groups at the active centre, since the ionization of these groups is likely to be influenced by the proximity of other charged groups. It is difficult, however, to visualize how trans-aconitate, etc., could produce such a large shift in the $\mathrm{p} K$ values. Nevertheless, evidence for such a dual reaction does exist, since citrate, which has been shown here to behave as a competitive inhibitor, will cause considerable activation of saltfree fumarase (Massey, 1953 $a$ ).

Such a duality of effect would account for the different $\mathrm{p} K$ values of the enzyme found with different compounds, and as will be shown later, it might also account for the different $\mathrm{pH}$ optima of fumarase with its two substrates. If such a reaction does occur, then what has been referred to throughout as free enzyme really means enzyme which is not combined at the active centre.

The possibility also exists that if substrates and inhibitors combine at groups other than the active centre, this secondary combination may affect the values of $K_{m}$ and $K_{i}$. In this case the measured values of $K_{m}$ and $K_{i}$ would not be the true values. Such an effect might contribute to the different values found under different conditions for the dissociation constants of groups in the 'free enzyme'.

The mechanism producing the observed changes in electrical charge associated with formation of $E S$ or $E I$ remains obscure. The inhibition by glycine suggests that glycine may be inhibiting by ionic attraction of its charged carboxyl group to one of the positively charged groups in the protein responsible for attraction of enzyme to substrate, and by attraction of its charged amino group to an acidic group at or close to the active centre. Presumably such a two-point attraction must occur. If glycine were to be attracted only by its carboxyl group, such a method of attraction should also apply to crotonate and the monomethyl ester of fumarate. However, this does not seem to occur, as no inhibition could be detected by these compounds. According to Dixon's theory the glycine-fumarase complex contains one more negative or one less positive group than the 'free' enzyme and free 
glycine. If the proposed acidic group in the protein were a weak acidic group such as a sulphydryl or a phenolic group, this would be unionized over most of the $\mathrm{pH}$ range investigated. However, bringing the strong positive charge of the amino group of glycine into the proximity of this potential negative group would be expected to cause it to ionize; the fumarase-glycine complex would then contain one more negative charge than the 'free' enzyme and glycine. However, no such positive group exists in the substrates to account for the similar slopes found with fumarate and malate.

If such an acidic group does exist at the active centre it is more likely to be a phenolic than a sulphydryl group for, contrary to the report of Laki (1941), no evidence could be obtained that crystallized fumarase contains a sulphydryl group essential for its activity. Iodoacetate, iodoacetamide, iodosobenzoate, $p$-chloromercuribenzoate and chloroacetophenone have all been tested on fumarase and found to be without effect.

If, as the evidence indicates, there is a secondary interaction of substrates and inhibitors which affects the ionization constants of groups at the active centre, it is obviously impossible to draw any rigorous conclusions about the chemical nature of the groups whose $\mathrm{p} K$ values have been determined. However, some tentative conclusions can be made. Fumarate and several inhibitors show $\mathrm{p} K$ values of some group in the 'free' enzyme about 6.0-6.7. The glyoxaline group of histidine is the only group known in proteins which has a $\mathrm{p} K$ value in this region, so that it is likely that this group occurs at the active centre of fumarase.

The existence of a glyoxaline group at the active centre is consistent with the changes of charge associated with formation of $E S$ or $E I$ complexes. At low $\mathrm{pH}$ values the glyoxaline group would be fully ionized and the attraction of substrate (or inhibitor) by a basic group in the enzyme adjacent to the glyoxaline group should not have any influence on the ionization of this glyoxaline group. However, at $\mathrm{pH}$ values above its $\mathrm{p} K$ the glyoxaline group would be becoming unionized. The 'neutralization' of an adjacent basic group would then tend to cause a re-ionization of the glyoxaline group; the $E S$ or $E I$ complex would then possess one more positive charge than the 'free' enzyme and substrate (or inhibitor).

These conclusions suggest the possibility of a grouping of charges at the fumarase active centre as shown in Fig. 4.

Such a grouping of charges might provide an explanation of the sequence of events associated with the enzymic reaction. Considering first the reaction starting with fumarate as substrate, fumarate is probably orientated at the active centre primarily by ionic attraction of its charged carboxyl groups to the positively charged groups 1 and 4 of the protein. This would bring the two $\alpha$-carbon atoms of fumarate in proximity to the proposed acidic and basic groups 2 and 3 . When both of these groups 2 and 3 are ionized they might be expected to exert a polarizing effect on the two $\alpha$-carbon atoms. Thus the carbon atom $\alpha_{1}$ would become electronpoor and the carbon atom $\alpha_{2}$ would become electronrich. This might be followed by the addition of water between the polarized carbon atoms, either as $\mathrm{H}^{+}$and $\mathrm{OH}^{-}$, or as the dipolar molecule of water, giving the fumarase-L-malate complex.

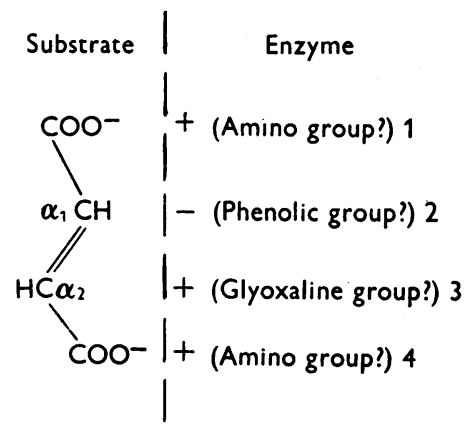

Fig. 4. A possible structure of the active centre of fumarase.

A similar mechanism might apply for the conversion of the L-malate complex to the fumarate complex. If the carbon atom which becomes electron-rich were the one to which the hydroxyl group is attached, the inherent electron-rich nature of the hydroxyl group should cause this to be split off by electrostatic repulsion, and a double bond between the two $\alpha$-carbon atoms would be formed. From this hypothesis, the $\mathrm{pH}$ of optimal activity would be expected to be where the polarizing effects of groups 2 and 3 are equal, that is, where they are equally ionized. From Figs. 2 and 3 it can be seen that two groups in $E S$ have $\mathrm{p} K$ values which are identical. Thus the enzyme-fumarate complex has two $\mathrm{p} K$ values at $7 \cdot 0$, and the enzyme-L-malate complex has two $\mathrm{p} K$ values at 8 . These $\mathrm{p} K$ values are approximately the same as the $\mathrm{pH}$ values of optimal activity for the two substrates (Massey, $1953 a$ ). Hence the two $\mathrm{p} K$ values of each enzymesubstrate complex may represent the $\mathrm{p} K$ values of the proposed groups 2 and 3 when the enzymesubstrate complex is formed, that is, the combination of enzyme and substrate would shift the $\mathrm{p} K$ of the glyoxaline group 3 to higher values, and the dissociation constant of (the phenolic?) group 2 to lower values.

\section{SUMMARY}

1. The following compounds have been found to be competitive inhibitors of fumarase: the sodium salts of D-malic, trans-aconitic, citric, mesaconic, maleic, adipic, glutaric, succinic, malonic and 
$D$-tartaric acids, glycine and the sodium salt of $\mathrm{L}-\alpha$-hydroxy- $\beta$-sulphopropionic acid.

2. Thiocyanate and the sodium salt of acetylenedicarboxylic acid were found to be non-competitive inhibitors.

3. The following compounds were found to be without effect on fumarase: the sodium salts of acetic, butyric, crotonic, $\mathrm{L}$ - and DL-aspartic, and acetoacetic acids, the mono- and di-methyl esters of fumarate, and the SH inhibitors, iodoacetate, iodoacetamide, iodosobenzoate, $p$-chloromercuribenzoate and chloroacetophenone.

4. The inhibition of all the competitive inhibitors was dependent on the temperature. Of the three inhibitors investigated in detail at low temperatures the combination of fumarase and inhibitors was found to be exothermic, while at higher temperatures the combination was found to be endothermic.
5. Inhibition by all the competitive inhibitors tested was markedly dependent on $\mathrm{pH}$. The variation of the inhibitor constants and of the Michaelis constants with $\mathrm{pH}$ has been studied in detail, and the results are discussed in the light of the theory of Dixon (1953).

6. A tentative hypothesis of the structure of the active centre and the sequence of reactions which may accompany the reversible hydration of fumarate to L-malate is suggested on the basis of these results.

I am indebted to Dr M. Dixon, F.R.S., for his helpful advice and for his interest in this work. I also wish to thank him for information about his enzyme-substrate theory before publication. I am also grateful to other members of the department, in particular Dr G. Weber and Dr E. C. Webb for many helpful discussions. This work was carried out on a grant from the 'Commonwealth Scientific and Industrial Research Organization, Australia.

\title{
REFERENCES
}

Dixon, M. (1950). Multi-enzyme Systems. Cambridge Lineweaver, H. \& Burk, D. (1934). J. Amer. chem. Soc. 56, University Press.

Dixon, M. (1953). Biochem. J. 55, 161.

Laki, K. (1941). Enzymologia, 9, 141.

658.

Massey, V. (1953a). Biochem. J. 53, 67.

Massey, V. (1953b). Biochem. J. 53, 72.

\section{Absorption of Immune Globulin by the Young Lamb after Ingestion of Colostrum}

\author{
By E. F. McCARTHY AND E. I. McDOUGALL \\ The Lister Institute, London, * and the Rowett Research Institute, \\ Bucksburn, Aberdeenshire
}

(Received 26 November 1952)

The role of colostrum in promoting the well being of the young ruminant has been established mainly by work on the cow. It has been shown that these animals depend on the ingestion of colostrum soon after birth and the absorption of immune globulins from this secretion for a passive immunity which greatly favours their chances of survival of the critical first fow weeks of their life (Smith \& Little, 1922; Orcutt \& Howe, 1922). That a similar situation obtains in the sheep has been shown in three different ways; the immunological studies of Mason, Dalling \& Gordon (1930) and Schnieder \& Szathmary (1939); the work on the sodium sulphate salted-out protein fractions of Earle (1935) and the electrophoretic examinations of Charlwood \& Thomson (1948). In the present work these three methods have been combined in a study of the changes in the serum proteins of suckling lambs and

* Present address. Physiology Department, University College, Dublin. extended to a series of lambs receiving colostrum after various periods of delay. In relation to these changes, the existence and nature of any proteinuria in the young lambs has been investigated.

\section{METHODS •}

Salted-out nitrogen fractions. Serum protein, globulin and albumin $\mathrm{N}$ fractions were estimated by difference from the total N, 'globulin-free' $N$ and non-protein $N$ contents; these were determined by micro-Kjeldahl analysis of the following solutions representing a dilution of 1 in 21 of the serum sample: a dilution in normal saline, a globulin-free filtrate obtained after precipitation with saturated $\mathrm{MgSO}_{4}$ at $20^{\circ}$ overnight, and a protein-free filtrate obtained after precipitation with trichloroacetic acid (5 g./100 ml.). Colostrum $\mathrm{N}$ fractions were obtained by analysing a suitable dilution in saline in the same way as serum with the following addition: casein $\mathbf{N}$ was obtained by including the analysis of a caseinfree filtrate prepared by acidification of a dilution in saline with acetic acid. 